\section{Formation of Glucose Isomerase by Streptomyces sp.}

\section{Yoshiyuki TAKASAKI}

Fermentation Research Institute, Agency of Industrial Science and Technology, Ministry of International Trade and Industry, Inage-Higashi, Chiba City, Japan

Received August 30, 1973

It is well known that many kinds of microorganisms produce glucose isomerase* when they are cultured in a medium containing $\mathrm{D}$-xylose. In previous papers, ${ }^{1 \sim 3}$ the author reported that Streptomyces sp. YT-No. 5, which has the ability to assimilate xylan, produces glucose isomerase when it was cultured in a medium containing xylan or xylan-containing materials such as wheat bran, corn cobs, or corn husks etc. This strain produced xylanase in the culture fluid, however, it was found that the main product from xylan by this xylanase was xylobiose. On the basis of this finding, the formation of glucose isomerase by the strain with xylobiose and $\mathrm{D}$-xylose was investigated.

Cultivation of Streptomyces sp. YT-No. 5 and induction experiments of glucose isomerase were carried out as follows:

Streptomyces sp. YT-No. 5 was cultured on the reciprocal shaker in a medium containing $1 \mathrm{~g}$, polypeptone; $0.3 \mathrm{~g}, \mathrm{~K}_{2} \mathrm{HPO}_{4} ; 0.1 \mathrm{~g}, \mathrm{MgSO}_{4} \cdot 7 \mathrm{H}_{2} \mathrm{O}$ and $1 \mathrm{~g}$, glucose in $100 \mathrm{ml}$ of distilled water for $16 \mathrm{hr}$ at $30^{\circ} \mathrm{C}$. After cultivation the cells were collected by centrifugation, washed and resuspended in distilled water (cell concentration, $10 \sim 15 \mathrm{mg} / \mathrm{ml}$ as dry matter). Five milliliters of the cell suspension was added to $5 \mathrm{ml}$ of the induction medium containing $0.05 \mathrm{M}$, phosphate

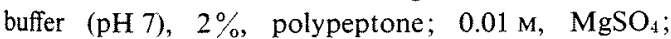
$0.002 \mathrm{M}, \mathrm{CoCl}_{2}$ and the indicated amount of xylobiose or D-xylose in the flask of $50 \mathrm{ml}$ capacity, and shaked at $30^{\circ} \mathrm{C}$ on a rotary shaker $(200 \mathrm{rpm})$. At every two hrs, $2 \mathrm{ml}$ of aliquots was taken out and the activity of glucose isomerase was assayed by the author's method previously reported. ${ }^{1 \prime}$

Figure 1 shows the time courses of formation of glucose isomerase by Streptomyces sp. YT-No. 5 with xylobiose and/or D-xylose. As clearly shown in this figure, not only $\mathrm{D}$-xylose but also xylobiose had the ability to induce glucose isomerase, and it was found that the presence of both xylobiose and D-xylose strong-

* According to the International Union of Biochemistry, Enzyme Commission in Enzyme Nomenclature, the enzyme may be classified as D-xylose ketolisomerase(the trival name, xylose isomerase, EC5.3.1.5). ly stimulated the formation of glucose isomerase.

Figure 2 shows the effect of concentration $\left(6 \times 10^{-4} \sim\right.$ $5 \times 10^{-1 \%} \%$ of xylobiose and D-xylose on the formation of glucose isomerase by Streptomyces sp. YT-No. 5 .

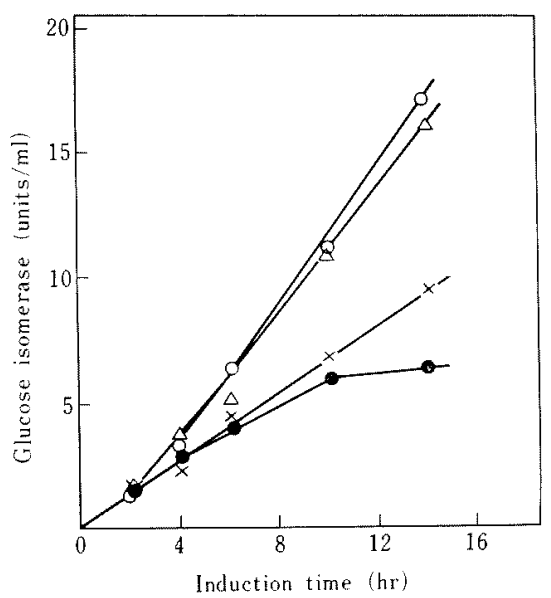

FIG. 1. Time Course of Induction of Glucose Isomerase of Streptomyces sp. YT-No. 5.

Experimental condition was the same as the standard condition except that the cell concentration was $5.6 \mathrm{mg}$ as dry matter.

$x-x$, xylobiose, $0.5 \%$; D-xylose, $0.5 \% ; 0-0$, xylobiose, $0.2 \%$; D-xylose, $0.3 \% ; \triangle-\triangle$, xylobiose, $0.1 \%$; D-xylose, $0.4 \%$.

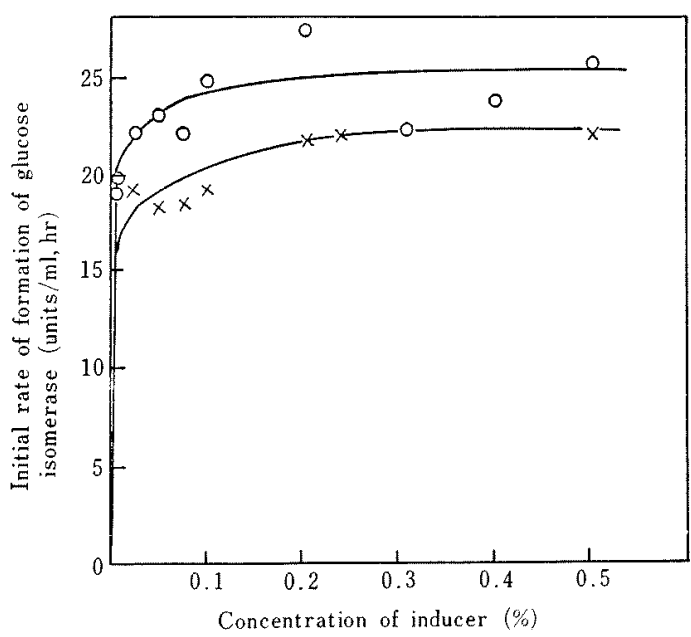

FIG. 2. Effect of Concentration of Xylobiose or D-Xylose on Formation of Glucose Isomerase of Streptomyces sp. YT-No. 5.

Experimental condition was the same as the standard condition except that the cell concentration was $4 \sim$ $7 \mathrm{mg}$ as dry matter.

$O-0$, xylobiose; $x-x$, D-xylose. 
As it is clear from the figure, the rate of formation of glucose isomerase with xylobiose was $10 \sim 15 \%$ larger than that with $\mathrm{D}$-xylose. The rates reached approximately maximum at around $0.02 \%$ of xylobiose or D-xylose concentration and remained almost constant at these concentrations. These optimal concentrations of the inducers for the inductive formation of glucose isomerase by Streptomyces sp. YT-No. 5 are very low compared with that of Bacillus coagulans, strain $\mathrm{HN}-68$, i.e., the optimal concentration of $\mathrm{D}$-xylose for the formation of glucose-isomerizing enzyme of Bacillus coagulans, strain HN-68 is around $2 \%{ }^{4}{ }^{4}$

Streptomyces sp. YT-No. 5 could produce glucose isomerase in good quantities even when the strain was cultured in a medium containing xylan. ${ }^{1 \sim 31}$ The reason for this result, may be that the maximal rate of forma tion of glucose isomerase by this strain is attained a a very low concentrations of inducer (such as $0.02 \%$ and such amounts of inducer (xylobiose) can be suffi ciently supplied by hydrolysis of xylan by the xylanast produced by this strain.

\section{REFERENCES}

1) Y. Takasaki, Agr. Biol. Chem., 30, 1247 (1966).

2) Y. Takasaki, ibid., 33, 1527 (1969).

3) "Fermentation Advances," ed. bỷ D. Perman Academic Press Inc., New York, 1969, p. 561.

4) G. Danno, Agr. Biol. Chem., 34, 1658 (1970). 